\title{
Influence of thermally induced oxygen order on mobile ion dynamics in $\operatorname{Gd}_{2}\left(\mathrm{Ti}_{0.65} \mathrm{Zr}_{0.35}\right)_{2} \mathrm{O}_{7}$
}

\author{
Karla J. Moreno, ${ }^{1}$ Antonio F. Fuentes, ${ }^{1}$ Miroslaw Maczka, ${ }^{2}$ Jerzy Hanuza, ${ }^{3}$ Ulises Amador, ${ }^{4}$ Jacobo Santamaría, ${ }^{5}$ and \\ Carlos León ${ }^{5, *}$ \\ ${ }^{1}$ Cinvestav Saltillo, Apartado Postal 663, 25000 Saltillo, Coahuila, Mexico \\ ${ }^{2}$ Institute of Low Temperature and Structure Research, Polish Academy of Sciences, P.O. Box 1410, 50-950 Wroclaw 2, Poland \\ ${ }^{3}$ Department of Bioorganic Chemistry, Faculty of Engineering and Economics, University of Economics, 53-345 Wroclaw, Poland \\ ${ }^{4}$ Departamento de Química, Facultad de Farmacia, Universidad San Pablo CEU, 28668 Boadilla del Monte, Madrid, Spain \\ ${ }^{5}$ GFMC, Departamento de Física Aplicada III, Facultad de Física, Universidad Complutense de Madrid, 28040 Madrid, Spain
}

(Received 24 August 2006; revised manuscript received 23 February 2007; published 15 May 2007)

\begin{abstract}
We report on the influence of oxygen order in the oxygen-ion dynamics in the ionic conductor $\mathrm{Gd}_{2}\left(\mathrm{Ti}_{0.65} \mathrm{Zr}_{0.35}\right)_{2} \mathrm{O}_{7}$. The metastable $\mathrm{Gd}_{2}\left(\mathrm{Ti}_{0.65} \mathrm{Zr}_{0.35}\right)_{2} \mathrm{O}_{7}$ powders prepared by mechanical milling present an anion-deficient fluorite type of structure, stable up to about $800{ }^{\circ} \mathrm{C}$. Thermal treatments at higher temperatures facilitate the gradual rearrangement of the cation and anion substructures and the relaxation of mechanochemically induced defects. Interestingly, metastable pyrochlores showing a very unusual cation distribution were observed during the thermally induced defect-recovery process. We have found that the ionic conductivity due to mobile oxygen ions increases significantly with increasing sintering temperature from 800 to $1500{ }^{\circ} \mathrm{C}$ as a result of a systematic decrease in the activation energy for the dc conductivity from 1.23 to $0.78 \mathrm{eV}$. Electrical conductivity relaxation is well described by stretched exponentials of the form $\Phi(t)=\exp \left[-(t / \tau)^{1-n}\right]$, and the fractional exponent $n$ decreases systematically from $n=0.51$ to 0.18 with increasing sintering temperature. These results are explained in terms of weaker ion-ion interactions in the increasingly ordered structure of the samples sintered at higher temperatures, and point to the importance of structural disorder in determining the dynamics of mobile oxygen ions.
\end{abstract}

DOI: 10.1103/PhysRevB.75.184303

PACS number(s): 66.10.Ed

\section{INTRODUCTION}

In oxide-ion conductors, oxygen transport takes place by hopping to adjacent oxygen vacancies in the structure. Thus, long-range motion of oxygen ions is found to be thermally activated and results in a dc conductivity of the form $\sigma_{d c}$ $=\left(\sigma_{\infty} / T\right) \exp \left(-E_{d c} / k T\right)$, with high activation energies $E_{d c}$, typically of the order of $1 \mathrm{eV}$. A priori, the activation energy should be determined by the energy barrier that oxygen ions must overcome to hop to neighboring vacant sites, but other factors may also affect ion dynamics and consequently the values found for $E_{d c}{ }^{1-3}$ Here, we investigate the influence of structural order in oxygen hopping dynamics and their importance in determining the effective activation energy of long-range oxygen diffusion in oxide-ion conductors.

Among oxide-ion conductors, those of pyrochlore structure have been shown to be promising candidates to substitute materials currently used in fuel cells. ${ }^{4,5}$ Pyrochlore oxides $A_{2} B_{2} \mathrm{O}_{7}$ are a very large family of compounds showing a great variety of physical and chemical properties as a function of chemical composition and the existing atomic ordering (disordering) and oxygen vacancies. Thus, while some pyrochlores such as $\mathrm{Gd}_{2} \mathrm{Zr}_{2} \mathrm{O}_{7}$ are electronically insulating and fast high- temperature ionic conductors, others such as $\mathrm{Gd}_{2} \mathrm{Mo}_{2} \mathrm{O}_{7}$ display at room temperature a metallic conducting behavior. ${ }^{6,7}$ The fully ordered or "ideal" pyrochlore oxide $A_{2} B_{2} \mathrm{O}(1)_{6} \mathrm{O}(2)$ presents a cubic symmetry [symmetry group $(\mathrm{SG}): F d \overline{3} m]$ and can be described in terms of a superstructure of the ideal anion-deficient fluorite structure (cubic, SG: $F m \overline{3} m$ ) with twice the cell constant, $a \approx 10 \AA \AA^{7}$ From the two available sites, the larger cation is normally found at the eight-coordinated $A$ site $(16 c)$ located at the center of a scalenohedron, whereas the smaller cation occupies the sixcoordinated $B$ site $(16 d)$ at the center of a trigonal antiprism. The oxygen $\mathrm{O}(1)$ atoms occupy the $48 f$ site coordinated by two $B$ and two $A$ cations, whereas the $\mathrm{O}(2)$ atoms occupy the $8 a$ site, tetrahedrally coordinated by four $A$ cations. There is another anionic tetrahedral site $8 b[\mathrm{O}(3)]$, coordinated by four $B$ ions which is systematically vacant in ordered pyrochlores as opposed to anion-deficient fluorites where vacancies are randomly distributed throughout the anion substructure. However, different degrees of atomic disorder and high oxygen mobility can be obtained in systems of solid solutions by using the appropriate substitutions on the $A$ and $B$ sites. ${ }^{8}$ Thus, the $\mathrm{Gd}_{2} \mathrm{Ti}_{2} \mathrm{O}_{7}-\mathrm{Gd}_{2} \mathrm{Zr}_{2} \mathrm{O}_{7}$ system shows complete miscibility. The cation and anion substructures in the $\mathrm{Gd}_{2}\left(\mathrm{Ti}_{1-y} \mathrm{Zr}_{y}\right)_{2} \mathrm{O}_{7}$ solid solution disorder gradually as the $\mathrm{Zr}$ content increases, leading to the appearance of oxygen vacancies at $48 f$ sites which are known to be responsible for oxygen hopping and diffusion. ${ }^{5,9}$ Correspondingly, a marked increase in oxygen conductivity is observed in this system when $y \geqslant 0.3$, which has been related to the onset of the anion disordering. ${ }^{9}$

Mechanical milling allows preparing partially disordered and metastable $\mathrm{RE}_{2} \mathrm{Ti}_{2} \mathrm{O}_{7}$ pyrochlores, ${ }^{10}$ obtained otherwise only by chemical substitution, ion irradiation, or pressureinduced compression. ${ }^{9}{ }^{911}, 12$ We have reported in a previous work on the influence of chemically induced disorder $(\mathrm{Zr}$ substitution for $\mathrm{Ti}$ ) in oxygen dynamics, and consequently on the electrical properties, of the $\mathrm{Gd}_{2}\left(\mathrm{Ti}_{1-y} \mathrm{Zr}_{y}\right)_{2} \mathrm{O}_{7}$ series. ${ }^{13}$ In this work, we will present the evolution of the structural disorder in metastable $\mathrm{Gd}_{2}\left(\mathrm{Ti}_{0.65} \mathrm{Zr}_{0.35}\right)_{2} \mathrm{O}_{7}$ powders prepared by mechanical milling with postmilling thermal treatments. That is, for a fixed composition, disorder induced in the 
preparation process is systematically relieved by annealing and the electrical properties analyzed as a function of the structure and/or microstructure. The composition $\mathrm{Gd}_{2}\left(\mathrm{Ti}_{0.65} \mathrm{Zr}_{0.35}\right)_{2} \mathrm{O}_{7}$ was selected for the study because it lies close to the boundary between the fully ordered ideal and the "defect" pyrochlore stability fields found in the $\mathrm{Gd}_{2}\left(\mathrm{Ti}_{1-y} \mathrm{Zr}_{y}\right)_{2} \mathrm{O}_{7}$ solid solution for equilibrium phases. ${ }^{9}$ These facts make this composition an ideal system for investigating the possible influence of structural disorder on the oxygen hopping dynamics and thus on the long-range ionic transport. We investigate this issue by impedance spectroscopy, an appropriate technique to probe ion hopping dynamics, since the dispersive ac conductivity data allow obtaining information on the oxygen dynamics. ${ }^{13}$

\section{EXPERIMENT}

The $\mathrm{Gd}_{2}\left(\mathrm{Ti}_{0.65} \mathrm{Zr}_{0.35}\right)_{2} \mathrm{O}_{7}$ powders were prepared as described elsewhere, ${ }^{14}$ by dry milling a stoichiometric mixture of the constituent oxides (high-purity monoclinic $\mathrm{ZrO}_{2}$, anatase- $\mathrm{TiO}_{2}$, and $\mathrm{C}-\mathrm{Gd}_{2} \mathrm{O}_{3}$ ), in a planetary ball mill using zirconia vials and balls. Portions of these powder samples were subjected to postmilling thermal treatments at four selected temperatures $\left(800,1000,1200\right.$, and $1500{ }^{\circ} \mathrm{C}$; soaking time of $12 \mathrm{~h}$; heating and cooling rate of $2{ }^{\circ} \mathrm{C} / \mathrm{min}$ ) and analyzed as described below. The structural and microstructural features of the as-prepared materials were obtained from precise diffraction data obtained on a Bruker D8 highresolution x-ray powder diffractometer equipped with a position-sensitive detector (PSD) MBraun PSD-50M, using monochromatic $\mathrm{Cu} K \alpha_{1}$ radiation $(\lambda=1.5406 \AA)$ obtained with a germanium primary monochromator. The measured angular range, the step size, and counting times were selected to ensure enough resolution (the step size should be at least $1 / 10$ of the full widths at half maximum) and statistics. The instrumental contribution to line broadening was evaluated using NIST $\mathrm{LaB}_{6}$ standard reference material (SRM $660 \mathrm{a} ; \mu=1138 \mathrm{~cm}^{-1}$, linear absorption coefficient for $\mathrm{Cu} K \alpha_{1}$ radiation). The structural refinements were carried out by the Rietveld method using the FULLPROF program ${ }^{15}$ and taking into account, simultaneously, the effects of the sample microstructure on the diffraction patterns according to a phenomenological approach described in detail elsewhere. ${ }^{10,16}$

Electrical conductivity relaxation measurements were carried out by impedance spectroscopy, with a Solartron 1260 frequency response analyzer, on cylindrical pellets $(10 \mathrm{~mm}$ diameter and $\sim 1 \mathrm{~mm}$ thickness) sintered at 800, 1000, 1200, and $1500{ }^{\circ} \mathrm{C}$. Electrodes were made by coating opposite faces of the pellets with SPI-Chem ${ }^{\mathrm{TM}}$ conductive Pt paint and firing them at $800{ }^{\circ} \mathrm{C}$ to eliminate organic components and harden the Pt residue. Data were recorded for each sample from 250 to $600{ }^{\circ} \mathrm{C}$ over the $100 \mathrm{~Hz}-1 \mathrm{MHz}$ frequency range. All measurements were made under $\mathrm{N}_{2}$ gas flow to ensure an inert atmosphere. Measurements were also done under air flow and no difference was observed.

Raman spectra were recorded with a Bruker FT-Raman RFS 100/S spectrometer. Excitation was performed with a $\mathrm{Nd}^{3+}$-doped yttrium aluminum garnet laser and the spectral resolution was $2 \mathrm{~cm}^{-1}$. Differential thermal analysis was performed in air in a Perkin-Elmer TAC/DX analyzer using a typical sample size of $10 \mathrm{mg}$ and a heating rate of $10{ }^{\circ} \mathrm{C} / \mathrm{min}$.

\section{RESULTS AND DISCUSSION}

\section{A. Structural characterization}

\section{1. $X R D$}

Figure 1 shows the x-ray-diffraction (XRD) patterns of the $\mathrm{Gd}_{2}\left(\mathrm{Ti}_{0.65} \mathrm{Zr}_{0.35}\right)_{2} \mathrm{O}_{7}$ samples obtained by ball milling and subjected to a $12 \mathrm{~h}$ thermal treatment at 800,1000 , and $1200{ }^{\circ} \mathrm{C}$. Results obtained from the structural refinements are collected in Table I together with their microstructural features obtained from the corresponding Langford plots. ${ }^{17,18}$ As the pyrochlore structure can be considered as a superstructure of an anion-deficient fluorite like atomic arrangement, its diffraction pattern contains a set of strong peaks characteristic of the fluorite-type substructure plus an additional set of superstructure reflections. The intensities of the latter depend on factors such as the degree of ordering, difference in the average scattering factors of the elements involved, distribution of oxygen vacancies, etc. ${ }^{8}$ Since no superstructure peaks due to the pyrochlore long-range atomic ordering are evident in Fig. 1(a), we might conclude that the as-prepared $\mathrm{Gd}_{2}\left(\mathrm{Ti}_{0.65} \mathrm{Zr}_{0.35}\right)_{2} \mathrm{O}_{7}$ powders present an aniondeficient fluorite type of structure which remains stable, at least, up to a temperature of $800{ }^{\circ} \mathrm{C}$. No additional phases are apparently present. As Figs. 1(b) and 1(c) show, powders treated at higher temperatures present XRD patterns containing all the characteristic reflections of pyrochlore-like materials [note the (331) peak in the inset of both figures]. As the structure factors $\left(F_{h k l}\right)$ of the superstructure peaks depend on the difference of scattering power between the $16 c$ and the $16 d$ sites and those of peaks with $h, k$, and $l$ even depend on the addition of the scattering power in both positions (constant along the whole series as the composition is), the relative intensity of the superstructure peaks is a direct evidence of the cation distribution in the structure. Therefore, judging from the relative intensity of their superstructure peaks, samples fired at 1000 and $1200{ }^{\circ} \mathrm{C}$ show different cation distributions. As mentioned before and based merely on metal ion size, one would expect the $16 c$ site in pyrochlores to be fully occupied by the larger $\mathrm{Gd}^{3+}$ ions, whereas the smaller $\mathrm{Ti}^{4+}$ and $\mathrm{Zr}^{4+}$ ions would share the hexacoordinated position $(16 d) \quad\left[\left(r\left(\mathrm{Ti}^{4+}\right)=0.61 \AA\right), r\left(\mathrm{Zr}^{4+}\right)=0.72 \AA\right.$, and $r\left(\mathrm{Gd}^{3+}\right)=0.94 \AA$, all in octahedral coordination]. ${ }^{19}$ Therefore, as a starting model for our refinements, we assumed all the $\mathrm{Gd}$ ions to be constrained into the $16 c$ site and correspondingly, the existing $\mathrm{Ti}$ and $\mathrm{Zr}$ ions sharing the $16 d$ position, but it became evident during the process that much more scattering power should be located in the $16 d$ site which could only be accomplished by allowing Gd ions to move into the latter and consequently, removing either $\mathrm{Ti}$ or Zr. From crystallochemical considerations, the obvious choice was $\mathrm{Zr}$ and we refined the occupation of both sites allowing $\mathrm{Zr}$ to move to the $16 \mathrm{c}$ site and $\mathrm{Gd}$ to occupy the $16 d$ position. The final refined distribution presented in Table 

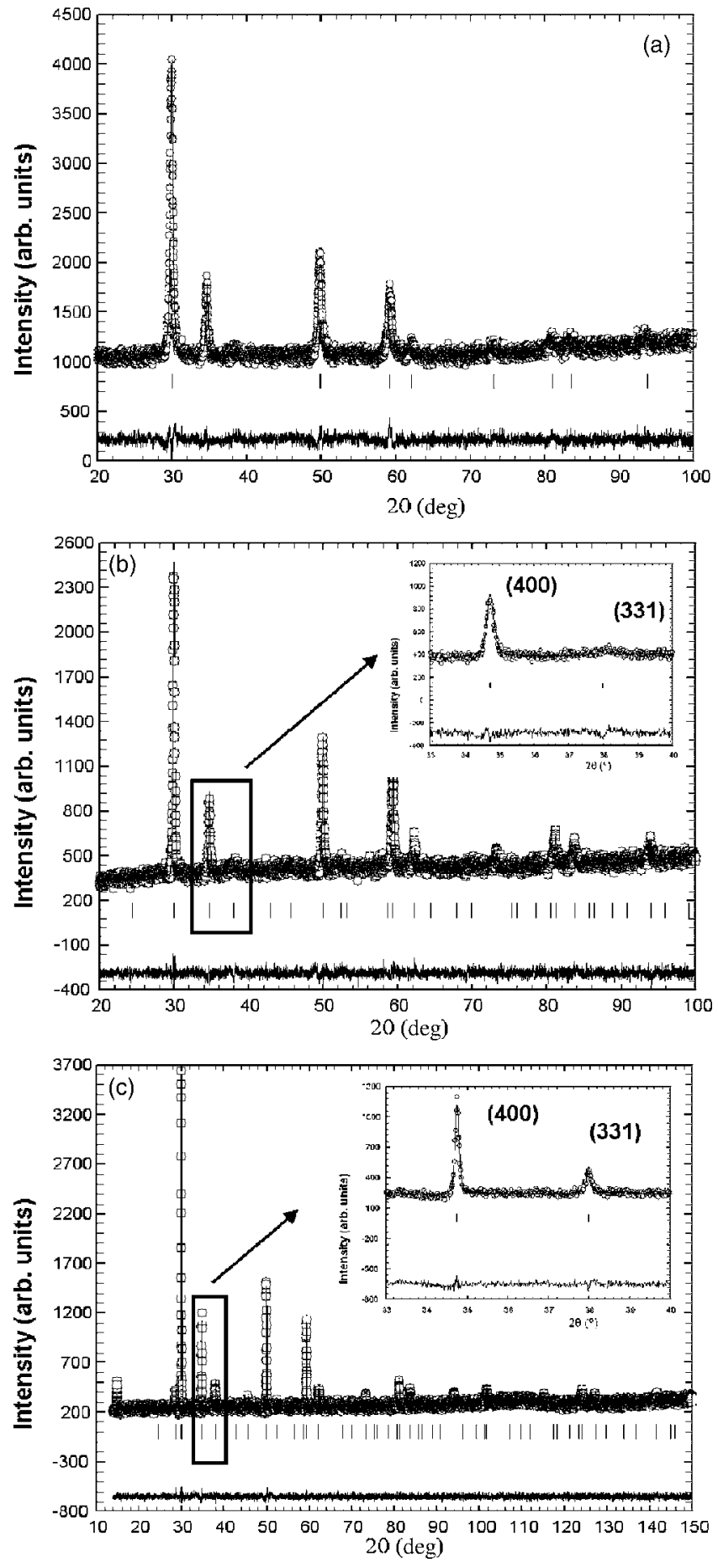

FIG. 1. Experimental (points), calculated (solid line), and difference (bottom) x-ray-diffraction patterns for as-prepared $\mathrm{Gd}_{2}\left(\mathrm{Ti}_{0.65} \mathrm{Zr}_{0.35}\right)_{2} \mathrm{O}_{7}$ powder sample fired at (a) 800, (b) 1000 , and (c) $1200{ }^{\circ} \mathrm{C}$. In the inset of (b) and (c), a zone of the pattern is magnified to show the relative intensity of the (331) pyrochlore superstructure peak.

I shows an important fraction of $\mathrm{Gd}$ ions to be located at the hexacoordinated $16 \mathrm{~d}$ site, even after firing the powder samples at very high temperatures (above $10 \%$ at $1500{ }^{\circ} \mathrm{C}$ ) and driving as a consequence a significant fraction of $\mathrm{Zr}^{4+}$ ions to the $16 c$ sites (above $30 \%$ at $1500{ }^{\circ} \mathrm{C}$ ). Therefore, although the structural refinement suggests a progressive ordering as the temperature of the postmilling thermal treatment increases, even the sample fired at $1500{ }^{\circ} \mathrm{C}$ presents a partially disordered cation sublattice as a result of the chemically (Zr substitution) and mechanically induced disordering. Regarding the microstructural features of these samples, data collected in Table I show that mechanochemically induced defects are difficult to relax and temperatures higher than $1200{ }^{\circ} \mathrm{C}$ are needed for the strain to decrease significantly, remaining essentially the same for the just-milled sample and for those fired at temperatures of up to $1000{ }^{\circ} \mathrm{C}$. On the contrary, the domain size varies gradually with the firing temperature (almost like an exponential growth as observed for many temperature-activated processes). As X-raydiffraction techniques are not adequate to study structural features related to light atoms such as oxygen, the oxygen array in our structural refinements is assumed to be ordered as in the ideal pyrochlore structure, whereas in fluorite, $1 / 8$ of the oxygen positions are empty at random.

\section{Raman spectroscopy}

We have performed Raman spectroscopy measurements for the study of oxygen disorder, as described previously on pyrochlores and fluorites. ${ }^{10,20,21}$ Raman spectroscopy is especially suited for analyzing anion disorder in $A_{2} B_{2} \mathrm{O}(1)_{6} \mathrm{O}(2)$ pyrochlore oxides since their spectra are entirely produced by the vibrations of the anion substructure, whereas the $A$ and $B$ cations, whose site symmetry is $D_{3 d}$, give rise to nonactive Raman phonon modes. Vibrations of the oxygen atoms located at the $48 f$ positions with $C_{2 v}$ site symmetry, $\mathrm{O}(1)$, contribute to five phonon modes $\left(A_{1 g}+E_{g}+3 T_{2 g}\right)$, whereas those bonded to the $A$ cation, the $\mathrm{O}(2)$, give a single $T_{2 g}$ mode. As for fluorites, there is only one vibrational mode Raman active $\left(T_{2 g}\right)$; with the form of the anions vibrating against the symmetry-fixed cations, it is very easy to distinguish between both structural arrangements. On the other hand, it has been shown that the increasing occupancy of the initially vacant $8 b$ site in the pyrochlore structure gives rise to the development of a new and broad vibrational Raman band near $750 \mathrm{~cm}^{-1}$ which has been assigned to sevencoordinated $\mathrm{Ti}$ atoms. ${ }^{21}$

Raman spectra collected for our just-milled sample and those milled and thermally treated at 800,1000 , and $1200{ }^{\circ} \mathrm{C}$ are presented in Fig. 2. Spectra obtained for the just-milled sample and that fired at $800{ }^{\circ} \mathrm{C}$ show the presence of very broad bands near 340 and $750 \mathrm{~cm}^{-1}$ and are similar to that presented by Hess et al. for pure defect fluorite-type $\mathrm{Gd}_{2} \mathrm{Zr}_{2} \mathrm{O}_{7}$ prepared by sintering of oxides. ${ }^{20}$ However, firing above that temperature produces significant changes in the Raman spectra; i.e., new bands develop at 712, 520, and $436 \mathrm{~cm}^{-1}$ which undoubtedly point to the formation of a pyrochlore type of structure and are a clear indication of a phase transition on heating the as-prepared metastable $\mathrm{Gd}_{2}\left(\mathrm{Ti}_{0.65} \mathrm{Zr}_{0.35}\right)_{2} \mathrm{O}_{7}$ powders above $800{ }^{\circ} \mathrm{C}$. Interestingly enough, the band near $750 \mathrm{~cm}^{-1}$ remains present even after firing the sample at $1200{ }^{\circ} \mathrm{C}$ although much weaker and narrower, suggesting the presence of residual oxygen disordering even at this temperature. As shown by XRD, it is also clear here that there are some differences between samples 
TABLE I. Structural evolution of metastable $\mathrm{Gd}_{2}\left(\mathrm{Ti}_{0.65} \mathrm{Zr}_{0.35}\right)_{2} \mathrm{O}_{7}$ powders prepared by mechanical milling.

\begin{tabular}{|c|c|c|c|c|c|}
\hline $\begin{array}{l}\text { Treatment } \\
T\left({ }^{\circ} \mathrm{C}\right) / \text { time }(\mathrm{h})\end{array}$ & $800 / 12$ & & $1000 / 12$ & $1200 / 12$ & $1500 / 12$ \\
\hline Structural type & Fluorite & & Pyrochlore & & \\
\hline Symmetry & $F m 3 m$ (n. 225) & & $F d 3 m$ (n. 227) & & \\
\hline$a(\AA)$ & $5.1698(7)$ & $a(\AA)$ & $10.3208(2)$ & $10.3171(1)$ & $10.3171(1)$ \\
\hline $\begin{array}{l}\mathrm{Gd} / \mathrm{Ti} / \mathrm{Zr} \text { in } 4 a, \\
m 3 m,\left(\begin{array}{lll}0 & 0 & 0\end{array}\right), \text { Occ. }\end{array}$ & $0.5 / 0.65 / 0.35$ & 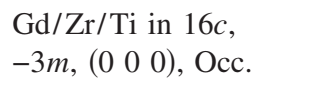 & $0.57(2) / 0.35 / 0.08(2)$ & $0.80(2) / 0.20(2) / 0.0$ & $0.87(1) / 0.13(1) / 0.0$ \\
\hline \multirow[t]{4}{*}{$\begin{array}{l}\mathrm{O}(1) \text { in } 8 c \\
-43 m\left(\frac{1}{4} \frac{1}{4} \frac{1}{4}\right) \\
\text { Occ. }\end{array}$} & $7 / 8$ & $\begin{array}{l}\mathrm{Gd} / \mathrm{Zr} / \mathrm{Ti} \text { in } 16 d, \\
-3 m,\left(\frac{1}{2} \frac{1}{2} \frac{1}{2}\right), \\
\text { Occ. }\end{array}$ & $0.43(2) / 0.0 / 0.57(2)$ & $0.20(2) / 0.15(2) / 0.65$ & $0.13(1) / 0.22(1) / 0.65$ \\
\hline & & $\begin{array}{l}\mathrm{O}(1) \text { in } 48 f, \\
m m(\times 1 / 81 / 8), \text { Occ. }\end{array}$ & 1 & & \\
\hline & & $x$ & $0.415(2)$ & $0.417(1)$ & $0.416(1)$ \\
\hline & & $\begin{array}{l}\mathrm{O}(2) \text { in } 8 a \\
-43 m,(1 / 81 / 81 / 8) \\
\text { Occ. }\end{array}$ & 1 & & \\
\hline$R_{B}$ & 0.048 & & 0.054 & 0.055 & 0.053 \\
\hline$R_{\mathrm{wp}}$ & 0.034 & & 0.050 & 0.062 & 0.044 \\
\hline$R_{\text {exp }}$ & 0.029 & & 0.047 & 0.059 & 0.042 \\
\hline$\chi^{2}$ & 1.33 & & 1.12 & 1.13 & 1.09 \\
\hline$\left\langle D_{\text {iso }}\right\rangle(\AA)^{\mathrm{a}}$ & $150(20)$ & & $145(4)$ & $284(20)$ & $3800(300)$ \\
\hline$e_{\mathrm{rms}}^{\mathrm{b}}$ & $5(1) \times 10^{-3}$ & & $3(2) \times 10^{-3}$ & $1(1) \times 10^{-4}$ & $1(1) \times 10^{-4}$ \\
\hline
\end{tabular}

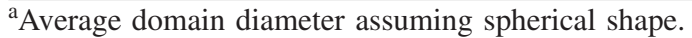

${ }^{b}$ Root-mean-square strain.

fired at 1000 and $1200{ }^{\circ} \mathrm{C}$; i.e., the Raman spectrum of the latter shows higher intensity of the $520 \mathrm{~cm}^{-1}$ band, lower intensity of the band near $750 \mathrm{~cm}^{-1}$, and smaller bandwidth of the $430 \mathrm{~cm}^{-1}$ band when compared with the sample fired

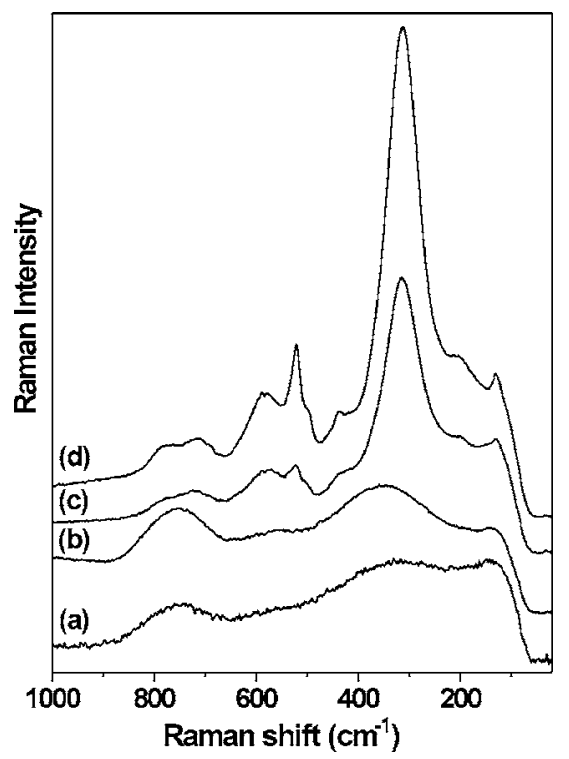

FIG. 2. Raman spectra obtained for the $\mathrm{Gd}_{2}\left(\mathrm{Ti}_{0.65} \mathrm{Zr}_{0.35}\right)_{2} \mathrm{O}_{7}$ samples (a) just milled and for the same sample but subjected to postmilling thermal treatments at (b) $800{ }^{\circ} \mathrm{C}$, (c) $1000{ }^{\circ} \mathrm{C}$, and (d) $1200{ }^{\circ} \mathrm{C}$. at $1000{ }^{\circ} \mathrm{C}$. These changes indicate that the ordering process is continuous, involving not only the metal substructure but also the anion sublattice.

The presence in the differential thermal analysis curve of an exothermic event confirms the existence of a phase transition on heating the as-prepared $\mathrm{Gd}_{2}\left(\mathrm{Ti}_{0.65} \mathrm{Zr}_{0.35}\right)_{2} \mathrm{O}_{7}$ powders at temperatures close to $860{ }^{\circ} \mathrm{C}$ (see Fig. 3). This event was also observed on disordered $A_{2} \mathrm{Ti}_{2} \mathrm{O}_{7}$ pyrochlores $(A$

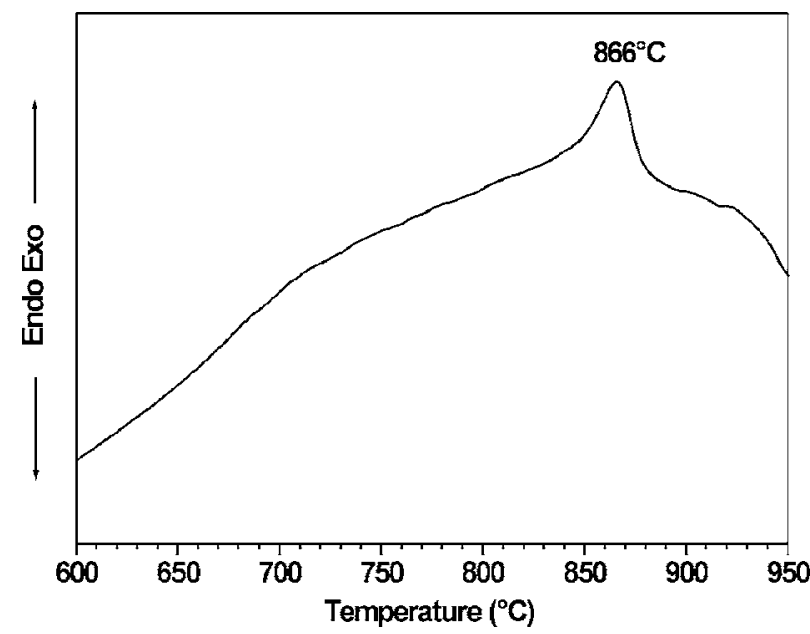

FIG. 3. Differential analysis curve obtained for the as-prepared $\mathrm{Gd}_{2}\left(\mathrm{Ti}_{0.65} \mathrm{Zr}_{0.35}\right)_{2} \mathrm{O}_{7}$ powders showing the presence of an exothermic event assigned to an anion-deficient fluorite to pyrochlore phase transition. 


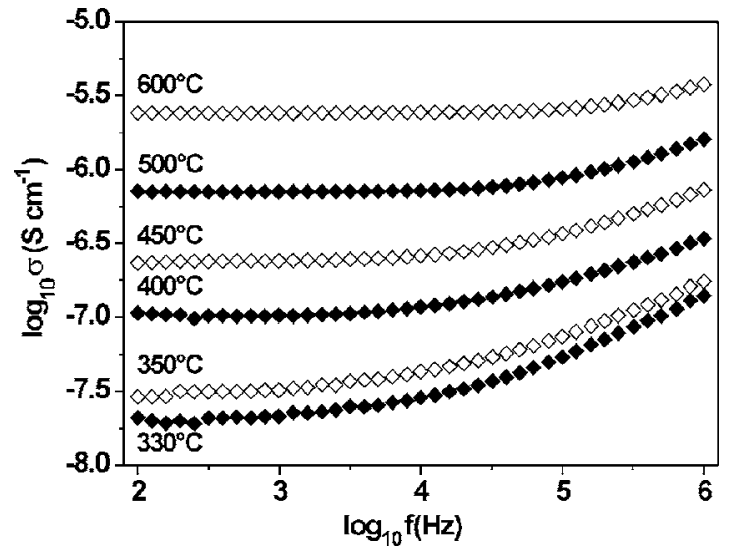

FIG. 4. Frequency dependence of the real part of the electrical conductivity $\sigma^{\prime}(\omega)$ at different temperatures for the as-prepared $\mathrm{Gd}_{2}\left(\mathrm{Ti}_{0.65} \mathrm{Zr}_{0.35}\right)_{2} \mathrm{O}_{7}$ powders sintered at $1500{ }^{\circ} \mathrm{C}$.

$=\mathrm{Gd}, \mathrm{Y}, \mathrm{Dy})$ prepared by mechanical milling and was associated mainly with an oxygen rearrangement process since it was present in $\mathrm{Y}_{2} \mathrm{Ti}_{2} \mathrm{O}_{7}$ and $\mathrm{Dy}_{2} \mathrm{Ti}_{2} \mathrm{O}_{7}$, showing cation and anion partially disordered substructures, as well as in $\mathrm{Gd}_{2} \mathrm{Ti}_{2} \mathrm{O}_{7}$, where disorder was constrained to the anion substructure. ${ }^{10}$ This disorder-order transition seems to be first order as evidenced by strong heat effects.

Hence, mechanochemically prepared $\mathrm{Gd}_{2}\left(\mathrm{Ti}_{0.65} \mathrm{Zr}_{0.35}\right)_{2} \mathrm{O}_{7}$ powders present an anion-deficient fluorite type of structure at room temperature and postmilling thermal treatments at temperatures higher than $\sim 860{ }^{\circ} \mathrm{C}$ facilitate long-range atomic ordering characteristic of pyrochlores. However, cation and anion orderings evolve at different rates. That is, while the anion substructure orders mostly in a narrow temperature range around $860{ }^{\circ} \mathrm{C}$, the ordering of the cation substructure is sluggish, and very high temperatures $\left(1500{ }^{\circ} \mathrm{C}\right)$ are needed to complete the process. This is most likely related to the well-known extremely slow rate of cation diffusion in fluorite-related stabilized zirconia based materials.

\section{B. Electrical conductivity relaxation}

In order to study the influence of the increasingly ordered structure found when increasing sintering temperature on oxygen dynamics, we performed electrical conductivity relaxation measurements. Figure 4 shows the frequency dependence of the real part of the electrical conductivity $\sigma^{\prime}(\omega)$ at different temperatures for the as-prepared $\mathrm{Gd}_{2}\left(\mathrm{Ti}_{0.65} \mathrm{Zr}_{0.35}\right)_{2} \mathrm{O}_{7}$ powders sintered at $1500{ }^{\circ} \mathrm{C}$, selected as representative of the series; similar plots were obtained for all the samples sintered at different temperatures and analyzed in this work. It can be observed that at high frequencies and/or low temperatures, isothermal conductivity data curves show a Jonscher-type ${ }^{22}$ power-law dependence of the form $\sigma^{\prime}(\omega) \propto \omega^{n}$ with a fractional exponent $n$. Increasing temperature and/or decreasing frequency leads to a regime with a frequency-independent conductivity value $\sigma_{d c}$, which is the bulk dc conductivity. Thus, $\sigma_{d c}$ at a given temperature can be directly obtained from ac conductivity measurements

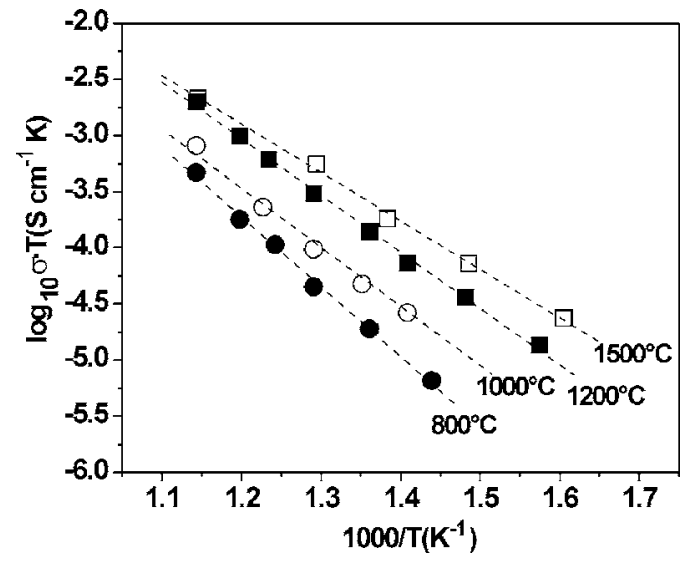

FIG. 5. Arrhenius plots showing the temperature dependence of the dc conductivity obtained for various samples sintered at different temperatures between 800 and $1500{ }^{\circ} \mathrm{C}$.

as the conductivity value in the "plateau" region of the isothermal curves in Fig. 4. We want to remark that conductivity values were not affected by measuring under $\mathrm{N}_{2}$ or air flows, and the electronic contribution to the conductivity, if any, was negligible, as determined by dc conductivity measurements using the same Pt electrodes. Figure 5 is an Arrhenius plot showing the temperature dependence of the ionic dc conductivity due to mobile oxygen ions for various samples sintered at different temperatures. All samples show a thermally activated behavior, $\sigma_{d c}=\left(\sigma_{\infty} / T\right) \exp \left(-E_{d c} / k T\right)$, and the activation energy, $E_{d c}$, for the dc conductivity is found to decrease from $1.23 \pm 0.04$ to $0.78 \pm 0.03 \mathrm{eV}$ as the sintering temperature increases from 800 to $1500{ }^{\circ} \mathrm{C}$.

The power-law frequency dependence observed in the ac conductivity in Fig. 4 has been previously related to the existence of cooperative effects in the dynamics of hopping ions, with the fractional exponent $n(0 \leqslant n<1)$ determined by the degree of ion-ion interactions existing in the ionic hopping process; i.e., in the absence of interactions among mobile ions (independent random ion hopping), the exponent $n$ would be 0 , while $n$ would tend to 1 for a completely correlated ion motion. ${ }^{23,24}$ An alternative representation of experimental conductivity data can be made by plotting the frequency dependence of the complex electric modulus, $M^{*}(\omega)$, which is directly related to the complex conductivity as $M^{*}(\omega)=1 / \varepsilon^{*}(\omega)=j \omega \varepsilon_{0} / \sigma^{*}(\omega)$, with $\varepsilon_{0}$ the permittivity of vacuum. The use of the electric modulus allows us to obtain the relaxation function $\Phi(t)$ in the time domain for the decay of the electric field inside the material under the constraint of a constant displacement vector. ${ }^{25,26}$ Under a constant displacement vector between the electrodes, ions will diffuse inside the material until a concentration gradient is created which cancels the electric field. Thus, the decay of the electric field [and its exact time dependence $\Phi(t)$ ] is related to how ions can diffuse inside the material between the electrodes. It is found that the frequency dependence of the electric modulus is given directly by the Laplace transform of the time derivative of the relaxation function 


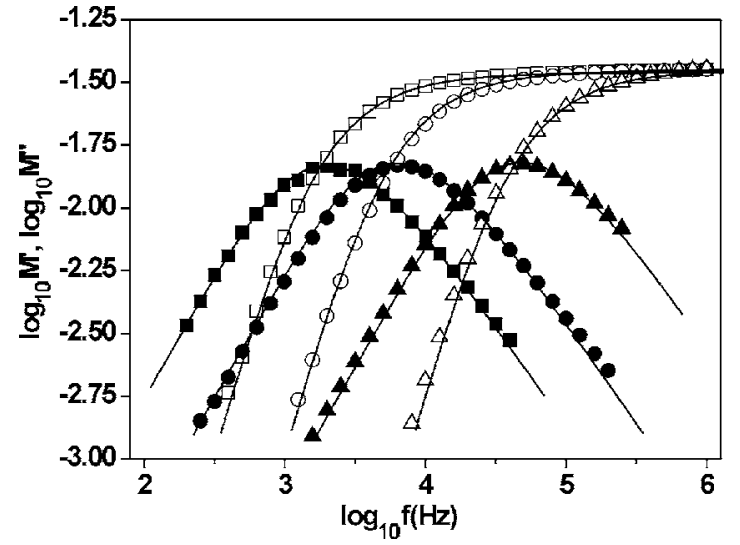

FIG. 6. Frequency dependence of the real (open symbols) and imaginary (solid symbols) parts of the electric modulus for the asprepared $\mathrm{Gd}_{2}\left(\mathrm{Ti}_{0.65} \mathrm{Zr}_{0.35}\right)_{2} \mathrm{O}_{7}$ powders sintered at $1500{ }^{\circ} \mathrm{C}$ at selected temperatures (from left to right, 350,400 , and $500{ }^{\circ} \mathrm{C}$ ). Solid lines are best fits according to a KWW relaxation function.

$$
M^{*}(\omega)=\frac{1}{\varepsilon_{\infty}}\left[1-\int_{0}^{\infty}\left(-\frac{d \Phi}{d t}\right) e^{-j \omega t} d t\right],
$$

where $\varepsilon_{\infty}$ is the permittivity value at high frequencies, and therefore the spectral shape and characteristic time of the electric modulus are determined by the dynamics of mobile ions which we are interested in. The relaxation function $\Phi(t)$ in ionic conductors is usually found to be nonexponential and can be well described by Kohlrausch-Williams-Watts (KWW) functions ${ }^{26,27}$ of the form

$$
\Phi(t)=\exp \left[-(t / \tau)^{1-n}\right], \quad 0<(1-n) \leqslant 1 .
$$

The relaxation time $\tau$ is a characteristic time for the ion hopping process and it is therefore thermally activated with the same activation energy of the dc conductivity. The exponent $n$ in the KWW function gives rise to the power-law frequency dependence of the ac conductivity at the highest frequencies and is a measure of the departure from the pure exponential or Debye behavior expected for uncorrelated ion hopping.

Figure 6 shows the frequency dependence of the real and imaginary parts of the electric modulus for the same sample shown in Fig. 4, as-prepared $\mathrm{Gd}_{2}\left(\mathrm{Ti}_{0.65} \mathrm{Zr}_{0.35}\right)_{2} \mathrm{O}_{7}$ powders sintered at $1500{ }^{\circ} \mathrm{C}$, but only at three selected temperatures for clarity. An asymmetric peak is observed in the imaginary part $M^{\prime \prime}(\omega)$, with the maximum at a characteristic frequency $\omega_{p} \approx \tau^{-1}$ increasing with temperature. Solid lines in the figure are best fits to KWW functions, from which the exponent $n$ can be determined. The shape of the electric modulus, and thus the value of the exponent $n$, was found to be temperature independent within experimental error. The excellent agreement between the KWW fits and the experimental data can be observed. Interestingly, the value of the parameter $n$ was found to change significantly from sample to sample when sintered at different temperatures. The inset of Fig. 7 shows how the exponent $n$ decreases systematically from $0.51 \pm 0.01$ to $0.18 \pm 0.01$ when the sintering temperature increases from 800 to $1500{ }^{\circ} \mathrm{C}$. The main panel in the same

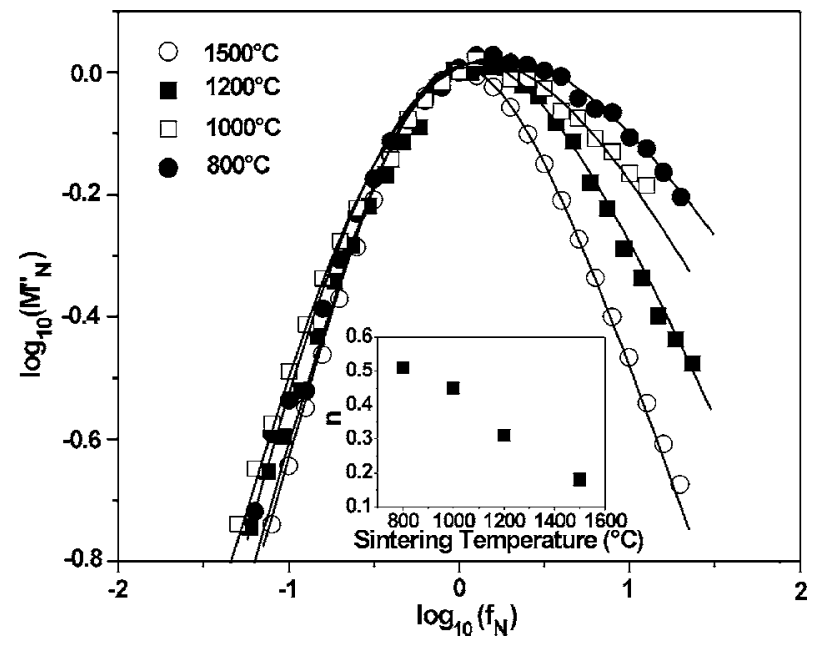

FIG. 7. Frequency dependence of the imaginary part of the electric modulus for as-prepared $\mathrm{Gd}_{2}\left(\mathrm{Ti}_{0.65} \mathrm{Zr}_{0.35}\right)_{2} \mathrm{O}_{7}$ powders sintered at different temperatures. Note that experimental data have been horizontally and vertically shifted by normalizing to the corresponding peak frequency and peak height values in each curve. Solid lines are fits according to a KWW relaxation function, and the inset shows the systematic and significant decrease in the value of the exponent $n$ in the KWW fit as the sintering temperature increases.

figure shows the frequency dependence of the imaginary part of the electric modulus for as-prepared powders sintered at the different temperatures, showing how the peak narrows with increasing sintering temperature. Peak narrowing corresponds to lower $n$ values in the KWW fit to electric modulus spectra.

It has been recently proposed that the different degrees of porosity (density) in ceramic samples might play a role in determining the values of the exponent $n \cdot{ }^{28}$ However, since density values range from $80 \%$ to $95 \%$ in our samples, only a small effect would be expected in the exponent $n$ as a consequence of microstructural differences, and a major role seems to be played, as discussed below, by changes in the degree of ion-ion correlations triggered by structural disorder. Interestingly, our results of the concomitant decrease of the activation energy $E_{d c}$ for the dc conductivity (see Fig. 5) and of the $n$ value (see inset of Fig. 7), as the sintering temperature is increased, can be rationalized in terms of the coupling model (CM). ${ }^{24,29,30}$ The CM starts with the consideration of the independent hops of ions to vacant adjacent sites with exponential correlation function, $\Phi(t)$ $=\exp \left(-t / \tau_{0}\right)$, and relaxation time $\tau_{0}$. Such independent hops cannot occur for all ions at the same time because of ion-ion interactions and correlations. The result of ion-ion interactions is the slowing down of the relaxation rate at times longer than $t_{c}$ of the order of $2 \mathrm{ps}$, changing the correlation function from a pure exponential to a KWW function, $\Phi(t)$ $=\exp \left[-(t / \tau)^{1-n}\right]$, wherein the value of the fractional exponent $n$ is a measure of the cooperative effects. A major result from the CM is that the effective relaxation time $\tau$ is related to $\tau_{0}$ by

$$
\tau=\left[t_{c}^{-n} \tau_{0}\right]^{1 /(1-n)} .
$$




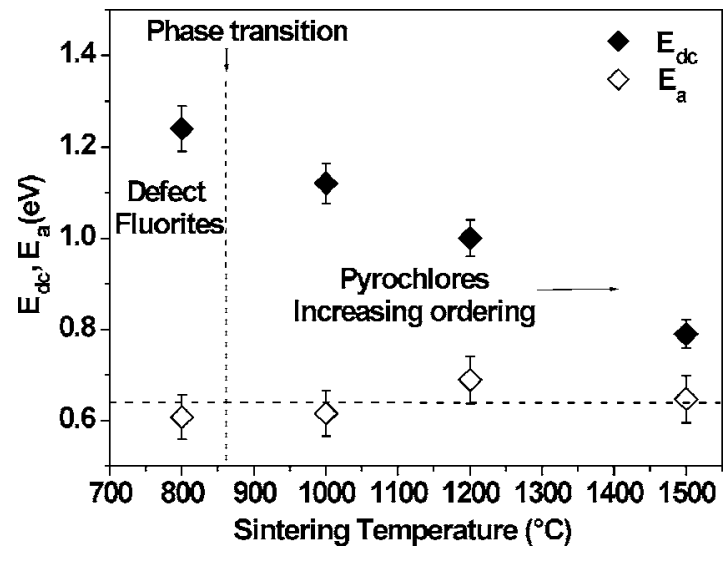

FIG. 8. Values obtained for the activation energy of the dc conductivity $E_{d c}$ and the energy barrier $E_{a}=(1-n) E_{d c}$ as a function of the sintering temperature. The horizontal dashed line represents the average $E_{a}$ value, whereas the vertical line represents the temperature of the phase transition observed when firing mechanochemically prepared $\mathrm{Gd}_{2}\left(\mathrm{Ti}_{0.65} \mathrm{Zr}_{0.35}\right)_{2} \mathrm{O}_{7}$ powders from a disordered fluorite to an increasingly ordered pyrochlore structure.

For ions vibrating in their cages and hopping to neighboring sites through barriers of energy $E_{a}$, the relaxation time for independent ion hopping is $\tau_{0}(T)=\tau_{\infty} \exp \left(E_{a} / k T\right)$. The reciprocal of $\tau_{\infty}$ is the attempt frequency of ions. It follows from Eq. (3) that the activation energy for the dc conductivity or $\tau$ will be larger than the energy barrier and is given by the relation

$$
E_{d c}=E_{a} /(1-n) .
$$

The increase of ion-ion interaction leads to a higher degree of cooperativity in the ion hopping process which corresponds to a higher value of $n$ and, consequently, to higher activation energy $E_{d c}$ for long-range ionic transport, due to the energy penalty that ion-ion interactions impose on the ionic diffusion process.

In fact, when we estimate the activation energy $E_{a}$ for the barrier that oxygen ions must overcome to hop (independently) between neighboring $48 f$ sites, according to Eq. (4) and by using the experimental values obtained for $E_{d c}$ and $n$, we find in all samples a value of $E_{a}=0.64 \pm 0.05 \mathrm{eV}$ that remains independent of the sintering temperature within experimental error. Figure 8 shows the values obtained for the energy barrier $E_{a}=(1-n) E_{d c}$ as a function of the sintering temperature, together with the values obtained for $E_{d c}$ from the Arrhenius fits in Fig. 5. As deduced from the structural characterization, a lower sintering temperature leads to a more disordered structure. The probability and direction of the hopping events performed by the mobile oxygen ions depend on their local potential landscape, which in a disordered structure will be determined by the distribution of other mobile ions in the neighboring oxygen sites. The hopping probability of a particular mobile ion will be strongly dependent on the position of the neighboring mobile ions (and therefore on the previous hopping events). Thus, ion dynamics becomes more correlated in a disordered structure, and consequently higher values of the exponent $n$ are expected according to the CM. The same argument explains the observed increase in the dc activation energy $E_{d c}$ when lowering the sintering temperature. A more disordered structure of the oxygen sublattice in samples sintered at lower temperatures (as described by the Raman spectra) fosters ion-ion correlations, and stronger correlations lead to an increase of the energy penalty imposed to the long-range or dc ionic conductivity, as observed for the dc activation energy $E_{d c}$. This explains the fact that the lower the sintering temperature, the larger the difference found between $E_{d c}$ and $E_{a}$ (higher value of $n$ ) as seen in Fig. 8.

\section{CONCLUSIONS}

We have shown in this work the feasibility of preparing metastable anion-deficient fluorite-type $\mathrm{Gd}_{2}\left(\mathrm{Ti}_{0.65} \mathrm{Zr}_{0.35}\right)_{2} \mathrm{O}_{7}$ powders by mechanical milling starting from constituent oxides. Postmilling thermal treatments allow some ordering to take place though both cation and anion substructures order at different rates: the first orders gradually with temperature, whereas the latter orders mostly around $860{ }^{\circ} \mathrm{C}$. Interestingly enough, transient pyrochlores with a very unusual cation distribution are obtained above $800{ }^{\circ} \mathrm{C}$. We have found that the activation energy for the dc conductivity decreases with increasing sintering temperature, thus leading to higher ionic conductivity values. From the analysis of electrical conductivity relaxation, we also found that there is a coupled decrease of the exponent $n$ in the KWW functions characterizing the dynamics of oxygen ions. This behavior is explained as due to the enhancement of ion-ion interactions promoted by the more disordered structure in samples sintered at lower temperatures.

\section{ACKNOWLEDGMENTS}

This work was supported by Mexican Conacyt (SEP2003-C02-44075) and Spanish MCYT (MAT2004-3070).
*Corresponding author. Electronic address: carletas@ fis.ucm.es

${ }^{1}$ A. V. Chadwick, Nature (London) 408, 925 (2000).

${ }^{2}$ J. B. Goodenough, Nature (London) 404, 821 (2000).

${ }^{3}$ K. L. Ngai, J. Non-Cryst. Solids 203, 232 (1996).

${ }^{4}$ P. K. Moon and H. L. Tuller, Solid State Ionics 28-30, 470 (1988).

${ }^{5}$ J. Chen, J. Lian, L. M. Wang, R. C. Ewing, R. G. Wang, and W.
Pan, Phys. Rev. Lett. 88, 105901 (2002).

${ }^{6}$ A. J. Burggraaf, T. van Dijk, and M. J. Verkerk, Solid State Ionics 5, 519 (1981).

${ }^{7}$ M. Subramanian, G. Aravamudan, and G. V. Subba Rao, Prog. Solid State Chem. 15, 55 (1983).

${ }^{8}$ B. J. Wuensch, K. W. Eberman, C. Heremans, E. M. Ku, P. Onnerud, E. M. E. Yeo, S. M. Haile, J. K. Stalick, and J. D. Jor- 
gensen, Solid State Ionics 129, 111 (2000).

${ }^{9}$ P. K. Moon and H. L. Tuller, in Solid State Ionics, edited by G. Nazri, R. A. Huggins, and D. F. Shriver MRS Symposia Proceedings No. 135 (Materials Research Society, Pittsburgh, 1989), p. 149.

${ }^{10}$ A. F. Fuentes, K. Boulahya, M. Maczka, J. Hanuza, and U. Amador, Solid State Sci. 7, 343 (2005).

${ }^{11}$ J. Lian, J. Chen, L. M. Wang, R. C. Ewing, J. M. Farmer, L. A. Boatner, and K. B. Helean, Phys. Rev. B 68, 134107 (2003).

${ }^{12}$ F. X. Zhang, B. Manoun, S. K. Saxena, and C. S. Zha, Appl. Phys. Lett. 86, 181906 (2005).

${ }^{13}$ K. J. Moreno, G. Mendoza-Suárez, A. F. Fuentes, J. GarcíaBarriocanal, C. León, and J. Santamaría, Phys. Rev. B 71, 132301 (2005).

${ }^{14}$ K. J. Moreno, R. Silva-Rodrigo, and A. F. Fuentes, J. Alloys Compd. 390, 230 (2005).

${ }^{15}$ J. Rodriguez-Carvajal, Physica B 19, 55 (1993); See also a report in CPD of IUCr, Newsletter 2001, 26, 12-19; available at http:// www.iucr.org/iucr-top/comm/cpd/Newsletters. The program and manual can be found at http://www-llb.cea.fr/fullweb/ powder.htm.

${ }^{16}$ S. García-Martín, M. A. Alario-Franco, H. Ehrenberg, J. Rodríguez-Carvajal, and U. Amador, J. Am. Chem. Soc. 126, 3587 (2004).

${ }^{17}$ J. I. Langford, Proceedings of the International Conference "Ac- curacy in Powder Diffraction II" (NIST, Gaithersburg, MD, 1992), NIST Special Publication No. 846.

${ }^{18}$ J. I. Langford, Defect and Microstructure Analysis by Diffraction, IUCr Monographs on Crystallography No. 10, edited by P. Snyder, F. Fiala, and H. Bunge (Oxford University Press, Oxford, 1999), pp. 59-81.

${ }^{19}$ R. D. Shannon, Acta Crystallogr., Sect. A: Cryst. Phys., Diffr., Theor. Gen. Crystallogr. A32, 751 (1976).

${ }^{20}$ N. J. Hess, B. D. Begg, S. D. Conradson, D. E. McCready, P. L. Gassman, and W. J. Weber, J. Phys. Chem. B 106, 4663 (2002).

${ }^{21}$ M. Glerup, O. F. Nielsen, and F. W. Poulsen, J. Solid State Chem. 160, 25 (2001).

${ }^{22}$ A. K. Jonscher, Dielectric Relaxation in Solids (Chelsea, London, 1983).

${ }^{23}$ K. Funke, J. Non-Cryst. Solids 172-174, 1215 (1994).

${ }^{24}$ K. L. Ngai and K. Y. Tsang, Phys. Rev. E 60, 4511 (1999).

${ }^{25}$ K. L. Ngai and C. León, Phys. Rev. B 60, 9396 (1999).

${ }^{26}$ P. B. Macedo, C. T. Moynihan, and R. Bose, Phys. Chem. Glasses 13, 171 (1972).

${ }^{27}$ R. Kohlrausch, Ann. Phys. 72, 353 (1847).

${ }^{28}$ D. P. Almond and C. R. Bowen, Phys. Rev. Lett. 92, 157601 (2004).

${ }^{29}$ K. L. Ngai and C. León, Phys. Rev. B 66, 064308 (2002).

${ }^{30}$ K. L. Ngai and C. León, J. Non-Cryst. Solids 315, 214 (2003). 